\title{
Effect of Silver Antibacterial Agents on Bond Strength of Fiber Posts to Root Dentin
}

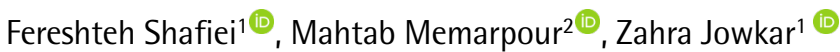

\begin{abstract}
This study was conducted to evaluate whether antibacterial pretreatment irrigation with silver nanoparticles (SNPs) and silver diamine fluoride (SDF) has any effect on bond strength of fiber posts cemented with three types of resin cements in root canal space. Fifty-four endodontically treated maxillary central incisor roots were prepared for fiber post (FRC Postec Plus NO.3, Ivoclar Vivadent) cementation and divided into nine groups in terms of three cement types and two pretreatments with silver antibacterial agents. The cements were as follows: an etch-and-rinse cement (ER, Excite DSC/Variolink N), a self-etch cement (SE, ED Primer/Panavia F2.0), and a self-adhesive cement (SA, Panavia SA Luting Plus). For each cement, the control group was with no treatment and two experimental groups were with SNPs and SDF treatments that were used after acid-etching for ER cement and after EDTA treatment for SE and SA cements. After fiber post cementation, each bonded root was horizontally sectioned into 1-mm thickness microslices to create two slices for each root region (apical, middle and coronal) and underwent push-out bond strength (PBS) test. Data in MPa were analyzed with two-way ANOVA and Tukey test $(p=0.05)$. The interaction of the pretreatment type and cement type was significant $(p<0.001)$. SNPs and SDF significantly increased PBS with ER cement $(p \leq 0.04)$. This positive effect was also marginally significant for SDF with SE cement $(p=0.049)$. For SA cement, SNPS showed a significant positive effect, but SDF had a significant adverse effect on PBS $(p<0.001)$. The effect of pretreatment with silver antibacterial agents prior to adhesive cementation of fiber posts depends on the resin cement used. Contrary to SNPs with beneficial or no significant effect on bonding for all cements, SDF exhibited a deleterious

effect with self-adhesive cement.
\end{abstract}

'Oral and Dental Disease Research Center, Department of Operative Dentistry, School of Dentistry, Shiraz University of Medical Sciences, Shiraz, Iran

${ }^{2}$ Oral and Dental Disease

Research Center, Department of Pediatric Dentistry, School of Dentistry, Shiraz University of Medical Sciences, Shiraz, Iran

Correspondence: Zahra Jowkar, Department of Operative Dentistry, School of Dentistry, Shiraz University of Medical Sciences, Shiraz, Iran Tel :+98-71-36263193. e-mail: zahrajowkar66@gmail.com

\section{Introduction}

An endodontically treated tooth that has suffered excessive loss of coronal tooth structure usually requires the use of an intra-canal post providing adequate support and retention for the restoration (1). Compared with the posts fabricated from metal, fiber-reinforced composite (FRC) posts have improved esthetic appearance with no risk of gingival discoloration and high flexural strength (2). Their similar elastic modulus to that of dentin minimizes the transmission of stresses to root wall along with adhesive ability to radicular dentin distribute stresses more homogenously in the root. This could diminish the probability of root fracture (2). The adhesive luting could improve post retention (3). Despite reports of clinical success with fiber post-reinforced restorations, debonding at the adhesive resin-dentin interface caused by difficulties regarding dentin hybridization has been reported as the most common cause of failure in the restoration with an FRC post (4). Meticulous chemo-mechanical disinfection and obturation of the root canal have been shown to be unable to eliminate bacterial biofilm (5). Also, during post preparation, a thick debris and smear layer formed possibly contains bacteria along with persistent bacteria in dentinal tubules. These in addition to the penetration of oral bacteria through coronal leakage might jeopardize the prognosis of endodontic treatment $(6,7)$. Moreover, an ex vivo study using a bacterial leakage model demonstrated that bacteria may still present in root canal space after immediate or delayed post-space preparation (7). These factors strongly necessitate the use of antibacterial agents in the root canal before post cementation. However, these agents should not adversely affect the bonding performance of resin materials to intraradicular dentin in the post space.

Sodium hypochlorite $(\mathrm{NaOCl})$ is the most popular used irrigant with a broad antibacterial spectrum (8). However, it alters chemical structure of dentin through degeneration/ dissolution of collagen and oxidizing effect arise concern regarding the bonding ability of resin materials to the pulp chamber or root dentin $(9,10)$. Chlorhexidine could be an alternative irrigant; however, its antibacterial efficacy is not durable due to not bioavailability, solubility and loosely electrostatic bond $(11,12)$.

A variety of silver-containing agents have been advocated for use in dentistry because of the bactericidal action of the silver ion $(\mathrm{Ag}+)$ (13-17). Silver diamine fluoride [Ag (NH3)2F] (SDF) has an intense antibacterial effect on 
cariogenic bacteria and can hinder the growth of cariogenic biofilm of S. mutans or Actinomyces naeslundii formed on dentine surfaces, hence prevent caries progression and dentin demineralization (18). It has potential to be used as intracanal antibacterial irrigant and is as effective as $\mathrm{NaOCl}$ against E. Faecalis biofilms (19). Pretreatment with SDF have also been found to increase the resistance of cavity margins around glass ionomer cement (GIC) restorations to secondary caries development (20). Furthermore, the bonding compatibility of SDF (38\%) treated noncarious dentin with self-etch (SE) and etch-and-rinse (ER) adhesive in resin composite restorations was indicated previously (21). However, the presence of black tooth discoloration following SDF application has been reported previously (22).

Recently, silver nanoparticles (SNPs) have attracted a great deal of attention from researchers in dentistry, mainly because of their long term antibacterial property via sustained silver $(\mathrm{Ag}+)$ release. Broad-spectrum bactericidal and virucidal properties of SNPs in low concentrations have been attributed to the multiple antibacterial mechanisms of silver such as cell wall permeability and the loss of the integrity of bacterial cell membrane caused by adherence and penetration into the bacterial cell wall, inactivation of the vital enzymes of bacteria and loss of DNA replication ability in the bacteria, leading to cell death $(13,23,24)$. Antibacterial efficacy of SNPs was reported to be 25 -fold higher than chlorhexidine (25). Also, SNPs are effective against several species of endodontic bacteria $(26,27)$. The biocompatibility of SNPs dispersion especially in a lower concentration has been demonstrated previously (28). Recently, it was shown that an additional pretreatment with SNPs could provide positive effects on the bond strength of both ER and SE adhesives with the best results obtained for Adper Single Bond and before acid etching (29). Also, it has been reported that SNPs could be used as a potent antibacterial agent before bonding procedures without compromising the bond strength of composite resin to dentin (16). However, one of the concerns about using SNPs as an antibacterial intracanal irrigant would be tooth discoloration (30).

To the authors' knowledge, there are no published studies that address the effect of SDF and SNPs pretreatments on the bond strength of the fiber post to root dentin using three types of resin cements. The purpose of this study was to assess the effect of SDF and SNPs root canal dentinal walls pretreatments on the retention of the FRC posts bonded with resin cements in the post space using push-out tests.

\section{Material and Methods}

Fifty-four sound human maxillary central incisors with anatomically similar shape and similar size with straight root without cracks and undeveloped apices were selected. Also, the teeth with coronal root canal diameter greater than 2 $\mathrm{mm}$ were excluded. They were used following approval of the research protocol (\#1396-01-99-14291) by the local Ethics Committee. The sample size for each experimental group was calculated based on a pilot study which was conducted using an etch-and-rinse resin cement (ER/ Excite DSC/ Variolink N) in three experimental groups $(n=5)$. In the first group (control), the cement was applied without any treatment. SNPs and SDF were applied before the application of the cement in the second and third groups, respectively. Five root sections were used in each group of the pilot study. The common standard deviation was 4.41 and the mean push-out bond strengths (PBSs) were 13.01 (ER cement + SNPs), 16.11 (ER cement + SDF) and 16.04 for the control. Considering $p$ value $=0.05$ and power of $80 \%$, the appropriate sample size of 31 root sections for each experimental group was calculated using compare means analysis.

The crowns were cut from the roots to provide a uniform length of $15 \mathrm{~mm}$ of the roots from the apical end and then the roots were endodontically treated at a working length of $-1 \mathrm{~mm}$ from the apical end. The crown down technique with an ISO size 30/0.07 taper was used for root canal preparation. The shaping of the root canals was performed using nickel-titanium rotary instruments (size S1, S2 and F3; Protaper, Dentsply-Maillefer, Ballaigues, Switzerland). Afterward, the Protaper Universal System (based on the sequence: S1 and SX for the 2/3 coronal third, and then, instruments $\mathrm{S} 1, \mathrm{~S} 2, \mathrm{~F} 1, \mathrm{~F} 2$, and $\mathrm{F} 3$ at the working length for the final preparation) was used to prepare the root canal spaces. Root canal irrigation during instrumentation was done with $5 \mathrm{~mL} 2.5 \% \mathrm{NaOCl}$ solution using a syringe with a $30-\mathrm{G}$ endodontic needle. Smear layer removal was performed using $3 \mathrm{~mL}$ of 17\% EDTA for 2 $\mathrm{min}$, followed by $3 \mathrm{~mL}$ of saline after root canal irrigation. Air stream and absorbent paper points (Dentsply-DeTrey, Konstanz, Germany) were used to completely dry the root canal spaces which were then obturated by lateral condensation of gutta-percha cones and a resin-based root canal sealer (AH-26, Dentsply-DeTrey). After sealing the coronal part of the roots with glass ionomer cement (Fuji VII, GC Corporation, Tokyo, Japan), the roots were stored in water for one week at $37^{\circ} \mathrm{C}$ and then the temporary coronal seal was removed.

After one-week water storage of the roots, post spaces were prepared to create a fixed depth of $10 \mathrm{~mm}$ using respective drills from the post manufacturer by the same trained operator, while remaining $4 \mathrm{~mm}$ of gutta-percha at the root end. This in addition confidence (being sure) of the cleanliness of the root canal wall was obtained by radiographs.

Fiber posts (FRC Postec Plus N0.3, Ivoclar Vivadent, 
Schaan, Liechtenstein) were tried in the prepared canal for a passive fit in the depth of $10 \mathrm{~mm}$. The specimens were randomly divided into nine groups $(n=6)$ based on two antibacterial intraradicular dentin treatment and three types of resin cements used; etch-and-rinse (ER/ Excite DSC/ Variolink N), self-etch (SE/ ED Primer II/Panavia F2.0) and self-adhesive (SA, Panavia SA Luting Plus). In the control groups (no treatment), three cements were used according to manufacturers' instructions, except for SE and SA cement that root space was irrigated with $1 \mathrm{~mL}$ of $17 \%$ EDTA for one minute using an endodontic syringe to remove the thick smear layer, rinsed and dried with absorbent paper points (31). In the three SNPs groups, the same cements were used; in SNPs groups, root dentin was pretreated with $5 \mathrm{~mL}$ of $1 \%$ SNPs solution for three minutes and then rinsed and dried. SNPs were used after acid-etching for ER and after EDTA irrigation for SE and SA cements. In the three SDF groups, root dentin was pretreated with $5 \mathrm{~mL}$ of $38 \%$ SDF (SaForide, Toyo Seigaku, Japan) solution for three minutes and then rinsed and dried. This step was done after acid-etching or EDTA irrigation.

SNPs were prepared as follows (29): after mixing quantities of sodium dodecyl sulfate (SDS) (Merck, Darmstadt, Germany) with $1 \mathrm{~g} / \mathrm{L} \mathrm{AgNO}_{3}$ in an aqueous solution under a $\mathrm{N}_{2}$ atmosphere, SDS molecules were applied to disperse the SNPs and also to stabilize the formation of shaped SNPs. Different reaction times were used for the deposition. After removal of Oxygen from the water by nitrogen bubbling, the electrolyte was combined under a nitrogen atmosphere. SDS was added at the 40 $\mathrm{g} / \mathrm{L}$ level to avoid aggregation. Distilled water was used to wash the products. The products were collected by centrifugation at $15000 \mathrm{rpm}$ for $10 \mathrm{~min}$ (Hettich Universal 320). The size, shape and the size distribution of the SNPs were examined using a transmission electron microscope (TEM, JEOL, JEM-1011; Japan). A uniform suspension of the nanoparticles was obtained after sonication of the solution of the nanoparticles to prepare samples for TEM imaging. Afterward, one drop of the sonicated nanoparticle solution was placed onto a TEM grid (200 mesh copper with a carbon support film) to evaluate the size, shape and the size distribution of the nanoparticles using TEM. Figure 1 shows the TEM image $(\times 300000)$ from the size, distribution, and shape of the SNPs.

In each group, the respective mixed cement was applied on the post surface and to the post space and then the post was immediately seated under finger pressure for 20 s. After removing the excess cement, light polymerization was carried out at $600 \mathrm{~mW} / \mathrm{cm}^{2}$ using a light curing unit (VIP Junior, Bisco, Schaumburg, IL, USA). The roots with cemented posts were sealed with Fuji II LC and then were stored in distilled water at $37^{\circ} \mathrm{C}$ for one week.

\section{Push-Out Test and Failure Mode Analysis}

The bonded roots were sectioned into seven $1 \mathrm{~mm}$ thick slices in a cutting machine (Mecatome T201 A, Persi, Grenoble, France) under water cooling to create two slices for each root region (apical, middle and coronal) $(n=36)$. The first slice was discarded. The slices were subjected to a compressive load in a universal testing machine (Zwick, Roell, Ulm, Germany) at $0.5 \mathrm{~mm} / \mathrm{min}$ at the center of the post in apico-coronal direction without contact on the surrounding cement or the root coronal walls until the shear stress along the bonded interface dislodged the post. The load at debonding in newton (N) was divided by the bonded area $\left(\mathrm{mm}^{2)}\right.$ and the PBS was recorded in MPa. The bonded area was calculated using the formula $\pi(R+r)[h 2+(R-r)$ 2]0.5, where $r$ and $R$ represent the apical and the coronal post radii, respectively, and $h$ is the thickness of the slice.

Each debonded specimen was examined under a stereomicroscope (Carl Zeiss, Oberkochen, Germany) at $40 \times$ magnification to determine the mode of failure. The failure modes were considered as follows: cohesive in dentin $(\mathrm{Cd})$, cohesive in cement $(\mathrm{Cc})$, adhesive in cementdentin interface (Ac-d), adhesive in cement-post (Ac-p), and mixed (M).

\section{Statistical Analysis}

Data were analyzed using two-way ANOVA and Tukey multiple comparisons with a significant level of 0.05 .

\section{Scanning Electron Microscope (SEM) Sample Preparation}

Representative debonded microslices from each experimental group were randomly selected to be prepared for SEM analysis. Wet silicon carbide paper of decreasing abrasiveness (up to 1200 grit was used to smooth the

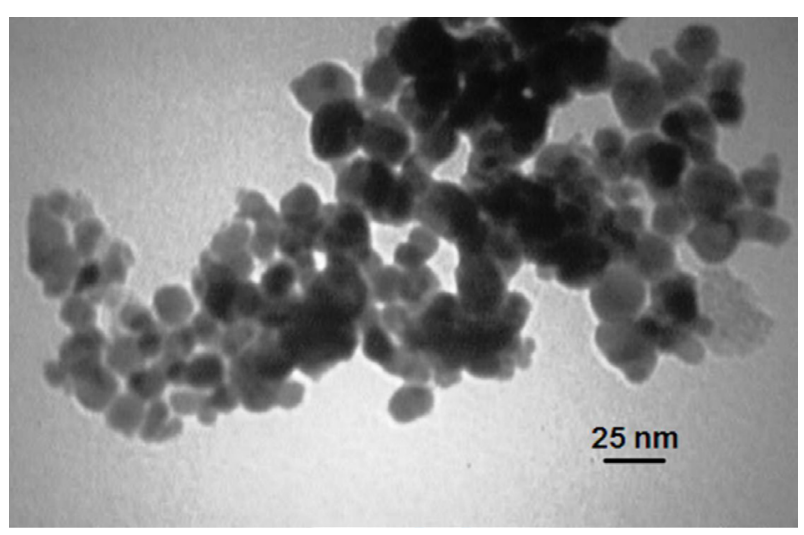

Figure 1. TEM image showing the distribution of spherical shaped SNPs with an average size of $20 \mathrm{~nm}$ ( $\times 300000$ magnification) 
surface of each microslice. In order to remove the mineral and organic components of dentin, the specimens were etched with a silica free $32 \% \mathrm{H}_{3} \mathrm{PO}_{4}$ (etching gel; Bisco) solution for $20 \mathrm{~s}$, immersed in $2.5 \% \mathrm{NaOCl}$ for $2 \mathrm{~min}$, and then rinsed with water. After dehydration with 99.8\% ethanol, the specimens were mounted on aluminum stubs, gold sputter coated and assessed under a scanning electron microscope (KYKY, EM3200, China).

\section{Results}

Table 1 shows the mean PBS values and standard deviation (SD) in MPa. At first, two-way ANOVA was used to analyze the effects of the two main factors (antibacterial treatment and cement type) and their interactions. The PBS was significantly influenced by antibacterial pretreatment $(p<0.001)$ but not by resin cement type $(p=0.19)$. The interaction of the two factors was significant $(p<0.001)$, meaning that the effect of each treatment depended on resin cement type. Accordingly, one way ANOVA and Tukey test for each cement revealed that both SNPs and SDF pretreatments significantly increased PBS of ER cement compared to that of control $(p=0.04$ and $p=0.009$, respectively); this increase was only marginally significant in SDF group for SE $(p=0.049)$. The two treatments had comparable bond strength for ER and SE cements ( $p>0.05)$. For SA cement, SNPs significantly increased the PBS compared to that of control $(p<0.001)$; however, SDF significantly decreased PBS $(p<0.001)$. Among control groups, SA cement showed a higher PBS compared to that of ER cement $(p=0.009)$. SA with SNPs had the highest bond strength (19.54 \pm 2.3$)$ with the significant difference

Table1. Push-out bond strength (mean \pm SD) in MPa for the nine study groups

\begin{tabular}{|c|c|c|c|c|c|c|c|}
\hline \multirow{2}{*}{ Cement } & \multirow{2}{*}{ Treatment } & \multirow{2}{*}{ Mean ( \pm SD) } & \multicolumn{5}{|c|}{ Failure Mode } \\
\hline & & & $\mathrm{Cd}$ & $\mathrm{Cc}$ & Ac-d & Ac-p & M \\
\hline \multirow{3}{*}{$\begin{array}{l}\text { Excite DSC/ } \\
\text { Variolink } \\
N(\text { ER) }\end{array}$} & $\begin{array}{c}\text { No } \\
\text { treatment }\end{array}$ & $13.27( \pm 3.04)$ & 3 & 3 & 8 & 3 & 19 \\
\hline & SNP & $15.57( \pm 3.94)$ & 4 & 2 & 6 & 2 & 22 \\
\hline & SDF & $16.17( \pm 4.02)$ & 4 & 2 & 4 & 1 & 25 \\
\hline \multirow{3}{*}{$\begin{array}{l}\text { ED Primer } \\
\text { II/ Panavia } \\
\text { F2.0 (SE) }\end{array}$} & $\begin{array}{c}\text { No } \\
\text { treatment }\end{array}$ & $14.33( \pm 3.20)$ & 5 & 2 & 7 & 2 & 20 \\
\hline & SNP & $16.49( \pm 4.25)$ & 5 & 1 & 4 & 4 & 22 \\
\hline & SDF & $16.72( \pm 4.26)$ & 4 & 1 & 3 & 2 & 26 \\
\hline \multirow{3}{*}{$\begin{array}{l}\text { Panavia } \\
\text { SA Luting } \\
\text { Plus (SA) }\end{array}$} & $\begin{array}{c}\text { No } \\
\text { treatment }\end{array}$ & $15.95( \pm 3.94)$ & 5 & 3 & 4 & 3 & 21 \\
\hline & SNP & $19.54( \pm 2.29)$ & 6 & 2 & 2 & 2 & 24 \\
\hline & SDF & $12.03( \pm 2.68)$ & 4 & 2 & 15 & 2 & 13 \\
\hline
\end{tabular}

$\mathrm{Cd}$ : cohesive in dentin; Cc: cohesive in cement; Ac-d: adhesive in cementdentin interface; Ac-p: adhesive in cement-post; M: mixed. with two other cements ( $p \leq 0.004)$, while SA with SDF had the lowest bond strength $(12.03 \pm 2.7)$ with a significant difference with two others $(p<0.001)$.

The stereomicroscope images (Figure 2) show dark discoloration of surrounding dentin of root slice from SDF group that this was slightly seen in the SNPs group.

Failure mode analysis revealed that most of the failures were mixed for all experimental groups except SA+SDF group in which the most common type of failure was adhesive in the cement-dentin interface.

\section{SEM Observation}

The morphological images of the root dentin-adhesive interface in the three cement types, ER, SE and SA (with no treatment and two silver treatments) are shown in Figures 3 to 5 , respectively. An intimate adaptation at the interface was seen in all the groups except for SA with SDF treatment group in which a gap was created at the interface.

\section{Discussion}

Silver-based antibacterial agents are effective against bacterial adhesion and preventing biofilm formation $(11,32)$. During FRC post adhesive cementation, it is possible to benefit from these properties. This was tested with three types of adhesive resin cements. In ER cement, acid etching has a potent antibacterial effect on residual bacteria (33). Moreover, acid etching and rinsing remove the thick smear layer; however, in SE and SA cements, the acidic monomers are applied directly on the smear layer (34). Therefore, in the current study, root canal space was irrigated to remove the smear layer before two latter cements (31). The acid etching/ EDTA and then water irrigation remove the smear layer, facilitating penetration of silver deposits to dentinal tubules. This was documented in a previous study for 3.8\% SDF for 24-72 $\mathrm{h}$ application time in root canal space (19). The considerable higher levels of silver and fluoride deposits were detected within demineralized dentin than normal dentin following SDF application (35). Silver is capable to form silver compounds with phosphate, chloride, oxide, and proteins that have relatively low solubility (36). These formed compounds within dentinal tubules may lead to a durable gradual release of slight silver ions $(19,36)$, providing long-term antibacterial efficacy in adhesive cement-sealed radicular dentin.

In light of obtained results, SDF pretreatment after acid-etching and before SE primer was effective in improvement of PBS of fiber post cemented with ER and SE cements. This result might be attributed to the occluding effect of silver deposits that limit intrinsic fluid movement at the adhesive interface. The similar approach with 
ER adhesive resulted in lower nanoleakage at the coronal dentin-adhesive interface with no effect on bond strength compared to that of control group (37). Permeability of the simplified ER adhesives was previously documented even in endodontically treated dentin. This may negatively affect the bonding of dual-cured resin cement to the root dentin (38). SNPs pretreatment might provide wettable surface and improve infiltration of adhesive resin into dentin surface and increase bond strength to coronal dentin. This could explain the higher PBS obtained in this study for used three types of cements compared to those of controls. However, the possible interference of silver deposits with chemical bonding of MDP functional monomer with the calcium of dentin might contribute to the insignificant

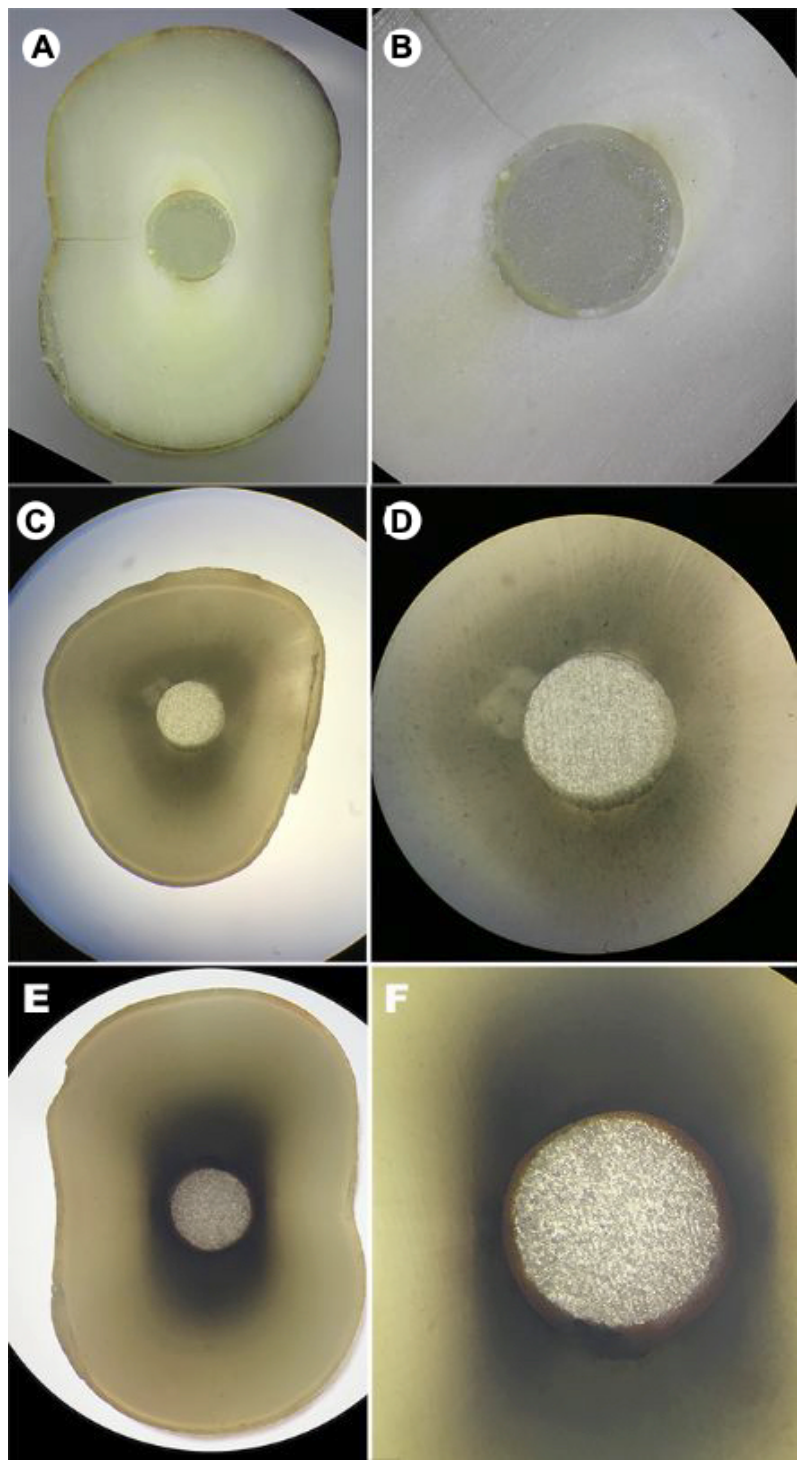

Figure 2. Stereomicroscope images $(\times 20$ and $\times 40)$ of three specimens from three study groups showing the color of surrounding dentin of the bonded post at two magnifications: Normal color in the control group (A and B), slight dark discoloration in SNPs group (C and D) and dark discoloration in SDF group (E and F) difference for SE cement group. The increased wettability is especially critical for SA cement because it is applied with no primer/adhesive. The high viscosity of the cement limits its interaction/penetration to dentin. In this way, SA could effectively benefit from the SNPs pretreatment. Contrary to SNPs, SDF decreased bonding ability of SA; this negative effect was only observed for this cement. It seemed that silver deposits hinder the chemical interaction of the acidic functional monomers of the cement with calcium of dentin structure. The calcium fluoride formed may limit availability of calcium ions. Furthermore, the water content of dentin is required to better ionize the acidic monomers of SA cements, resulting in increased interaction ability with dentin (39). Therefore, the occluding effect of SDF might limit the effective interaction of SA with root dentin. There is no previous publication about the effect of dentin pretreatment with SDF used as an antibacterial agent on the bonding performance of adhesive systems. One study demonstrated no effect of SDF treatment on bond strength to coronal dentin. In that study, acid-etching was applied after SDF treatment because it was based on the clinical relevance that prevention of caries with SDF treatment of dentin may affect the subsequent bond strength of adhesive restorations (21). However, in the present study as the first study, SDF was applied after acid-etching/ EDTA to maximize the elimination of bacteria in the post space. The major adverse effect of silver is reported to be potentially dark discoloration. This was clearly observed in the sectioned bonded root with SDF treatment under the microscope and even visually; however, the discoloration was less with $1 \%$ SNPs so that only was seen under the microscope not visually. The difference might be related to silver concentration (10 ppm) and nanometer size of silver in SNPs solution. Also, the discoloration was not reported to be seen visually in coronal dentin with the same concentration of SNPs applied for 1 min (29). However, the SNPs were applied for three minutes in the current study. The longer application time compared to the previously mentioned study might be responsible for slight dark discoloration observed under the microscope in the present study. Anyway, when comparing to coronal dentin, discoloration in the root area could not be a concern. 20-nm silver used in this study has powerful antibacterial activity due to large surface area and very intimate interaction with bacteria. Furthermore, 1\% SNPs dispersion (10 ppm) is biocompatible. SNPs in a concentration of $23 \mathrm{ppm}$ revealed acceptable biocompatibility (28). SNPs are almost insoluble in biologic fluids (25). In the present study, SDF was used in a concentration of $38 \%$, which revealed an inhibitory effect on matrix metalloproteinases with the highest effect compared to those of lower concentration. And this was demonstrated to preserve collagen from degradation 

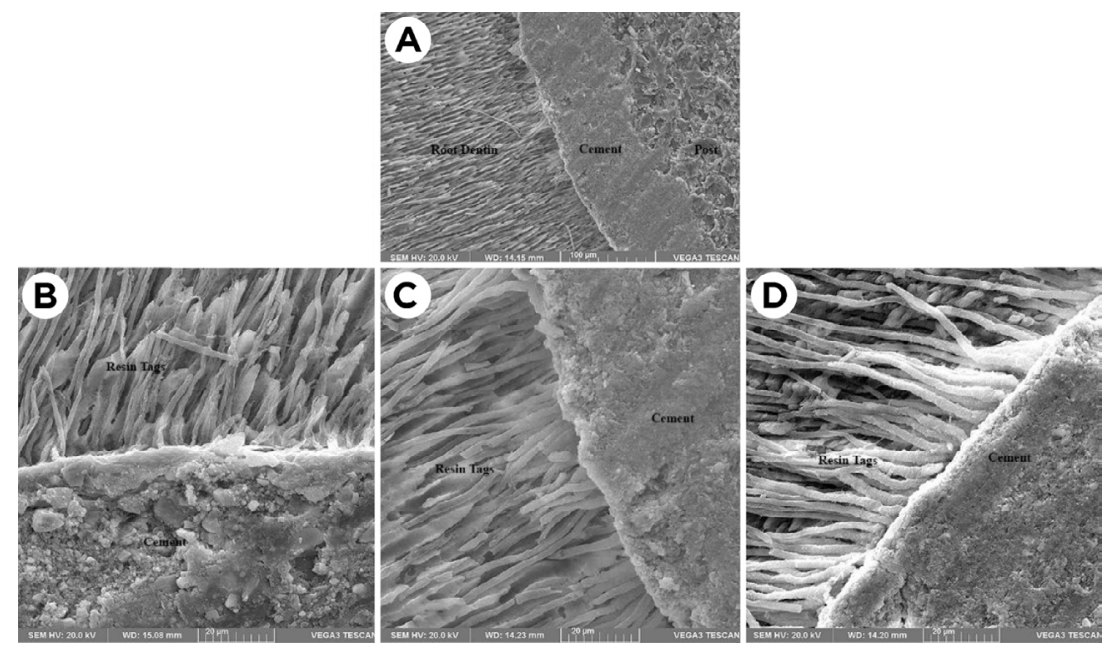

Figure 3. SEM images of the three groups at root dentin-ER cement interface: (A) post-cement-root dentin interface ( $\times 500)$; (B) not treated, intimate adaptation with numerous long resin tags $(\times 2000)$; (C) SNP treated $(\times 2000)$ and (D) SDF treated $(\times 2000)$, both well-adapted interface with more resin tags formation.

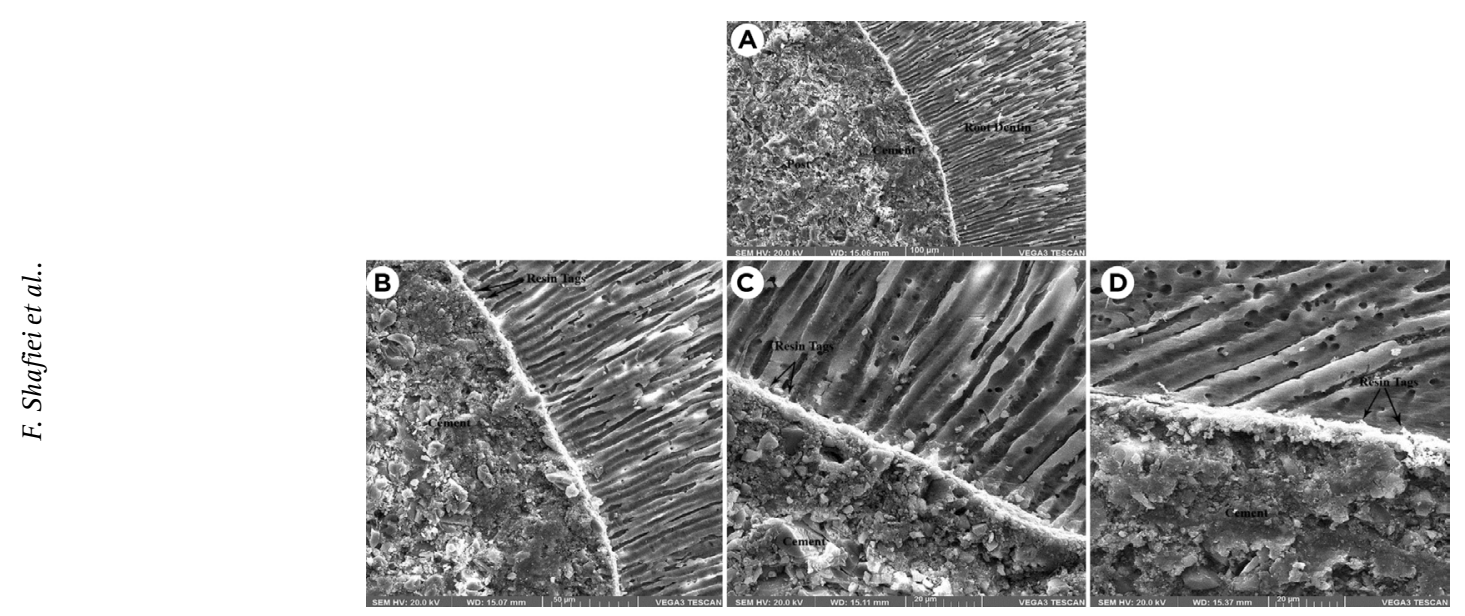

Figure 4. SEM images of the three groups at root dentin-SE cement interface: (A) post-cement-root dentin interface ( $\times 500)$; (B) not treated wellformed interface with a few short resin tags ( $\times 2000)$; (C) SNP treated $(\times 2000)$ and (D) SDF treated $(\times 2000)$, both similar to no treated interface.

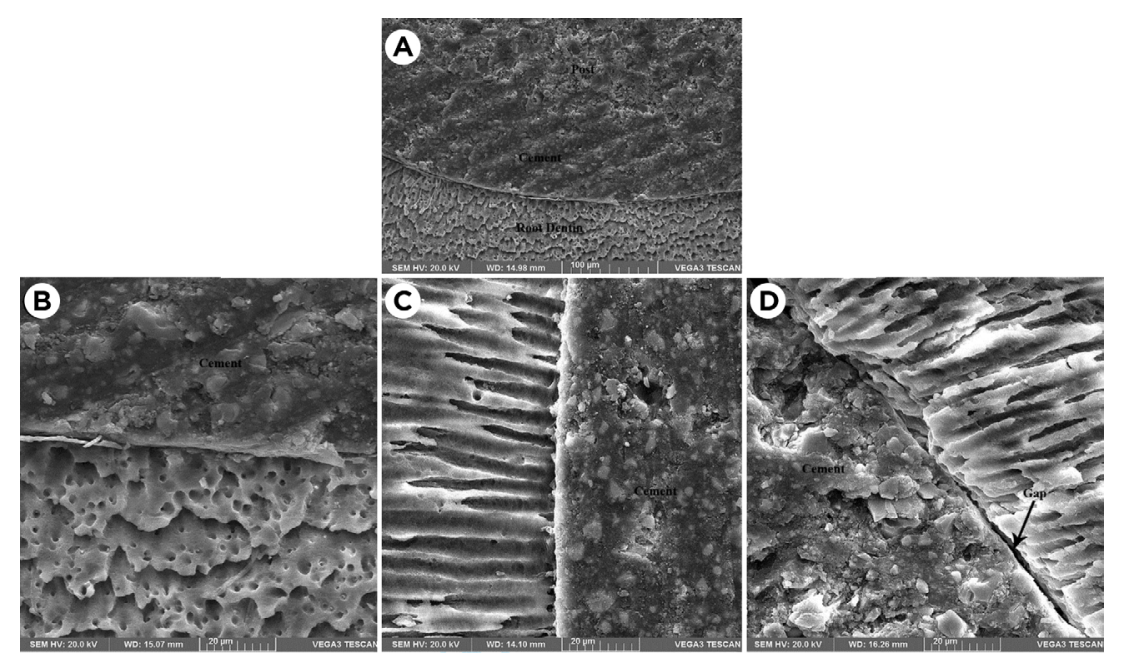

Figure 5. SEM images of the three groups at root dentin-SA cement interface: (A) post-cement-root dentin interface $(\times 500)$; (B) root treated $(\times 2000)$ and (C) SNP treated $(\times 2000)$ both well-adapted interface along the interface; (D) SDF treated ( $\times 2000)$, small gaps along the interface. 
$(40,41)$. This inhibitory effect was indicated against cysteine cathepsins in 38\%, 30\%, and 12\% concentrations of SDF equally (36). Inactivating the reactive side chain of the enzymes and their catalytic functions and blocking the active site of the collagens by silver ions (not F-) may be responsible for the beneficial effect $(36,41)$. These activities may prevent resin-dentin bond degradation, preserving bond stability. Hence, this hypothesis will be evaluated in the second part of the present study that is being performed at present through long term water storage of the similar groups of bonded root specimens.

This study had some limitations. The aging conditions (fatigue, water, and thermal aging) were not involved in this study and only the initial effect of silver antibacterial agents was evaluated. The clinical situations were not completely mimic in this study. In addition, one product from each cement type was assessed; therefore, the obtained results cannot be generalized to other cement systems. Longterm evaluations with considering clinical situations are necessary to achieve comprehensive results.

In conclusion, the effect of pretreatment with silver antibacterial agents prior to adhesive cementation of fiber posts depends on the resin cement used. Contrary to SNPs with beneficial or no significant effect on bonding for all cements, SDF exhibited a deleterious effect with self-adhesive cement.

\section{Resumo}

Este estudo foi conduzido para avaliar se a irrigação de pré-tratamento antibacteriano com nanoparticulas de prata (SNPs) e fluoreto de diamina de prata (SDF) tem algum efeito na resistência de união de pinos de fibra cimentados com três tipos de cimentos resinosos no espaço do canal radicular. Cinquenta e quatro raizes de incisivos centrais superiores tratadas endodonticamente foram preparadas para cimentação de pino de fibra (FRC Postec Plus N0.3, Ivoclar Vivadent) e divididas em nove grupos em termos de três tipos de cimento e dois pré-tratamentos com agentes antibacterianos de prata. Os cimentos foram os seguintes: um cimento etch-and-rinse (ER, Excite DSC / Variolink N), um cimento autocondicionante (SE, ED Primer / Panavia F2.0) e um cimento autoadesivo (SA, Panavia SA Luting Plus). Para cada cimento, o grupo controle foi sem tratamento e dois grupos experimentais foram com SNPs e SDF tratamentos que foram usados após o condicionamento ácido para o cimento ER e após o tratamento com EDTA para os cimentos SE e SA. Após a cimentação do pilar de fibra, cada raiz ligada foi seccionada horizontalmente em microclimas de $1 \mathrm{~mm}$ de espessura para criar duas fatias para cada região da raiz (apical, média e coronal) e submetida ao teste de resistência de união por push-out (PBS). Os dados em MPa foram analisados com ANOVA de dois fatores e teste de Tukey $(p=0,05)$. A interação do tipo de pré-tratamento e tipo de cimento foi significativa $(p<0,001)$. SNPs e SDF aumentaram significativamente o PBS com cimento ER $(p \leq 0,04)$. Este efeito positivo também foi marginalmente significativo para SDF com cimento $S E(p=$ 0,049 ). Para o cimento SA, os SNPs mostraram um efeito positivo significativo, mas o SDF teve um efeito adverso significativo no PBS $(p<0,001)$. 0 efeito do pré-tratamento com agentes antibacterianos de prata antes da cimentação adesiva dos pinos de fibra depende do cimento resinoso utilizado. Ao contrário dos SNPs com efeito benéfico ou nenhum efeito significativo na adesão para todos os cimentos, o SDF exibiu um efeito deletério com o cimento autoadesivo.

\section{Acknowledgments}

This project (Grant number: 1396-01-99-14291) was carried out by the financial support from the Vice-Chancellery of Research Shiraz University of Medical Sciences. The authors thank Dr. Mehrdad Vossoughi for statistical analysis of the data.

\section{References}

1. Williams C, Kumar M, Bajpai M, Agarwal D. Prosthodontic management of endodontically treated teeth: A literature review. Int J Clin Prev Dent 2014;10:45-50.

2. Maroulakos G, Nagy WW, Kontogiorgos ED. Fracture resistance of compromisedendodontically treated teeth restored with bonded post and cores: An in vitro study. J Prosthet Dent 2015;114:390-7.

3. Shafiei $F$, Mohammadparast $P$, Jowkar Z. Adhesion performance of a universal adhesive in the root canal: Effect of etch-and-rinse vs. selfetch mode. PloS One 2018;13:e0195367.

4. Naumann M, Koelpin M, Beuer F, Meyer-Lueckel H. 10-year survival evaluation for glassfiber-supported postendodontic restoration: a prospective observational clinical study. J Endod 2012;38:432-435.

5. Siqueira JF, Rôças IN, Ricucci D. Biofilms in endodontic infection. Endod Topics 2010;22:33-49.

6. Shafiei F, Memarpour M, Vafamand N, Mohammadi M. Effect of antibacterial/adhesive approaches on bonding durability of fiber posts cemented with self-etch resin cement. J Clin Exp Dent 2017;9:e1096-e1102.

7. Lyons W, Hartwell G, Stewart J, Reavley B, Appelstein C, Lafkowitz S. Comparison of coronal bacterial leakage between immediate versus delayed post-space preparation in root canals filled with Resilon/ Epiphany. Int Endod J 2009;42:203-207.

8. Gonçalves LS, Rodrigues RCV, Junior CVA, Soares RG, Vettore MV. The effect of sodium hypochlorite and chlorhexidine as irrigant solutions for root canal disinfection: a systematic review of clinical trials. J Endod 2016;42:527-532.

9. Ari $\mathrm{H}$, Yasar $\mathrm{E}$, Belli $\mathrm{S}$. Effects of $\mathrm{NaOCl}$ on bond strengths of resin cements to root canal dentin. J Endod 2003;29:248-251.

10. Martinho FC, Carvalho CA, Oliveira LD, de Lacerda AJ, Xavier AC, Augusto $M G$, et al. Comparison of different dentin pretreatment protocols on the bond strength of glass fiber post using self-etching adhesive. J Endod 2015;41:83-87.

11. Besinis A, De Peralta T, Handy RD. Inhibition of biofilm formation and antibacterial properties of a silver nano-coating on human dentine. Nanotoxicology 2014;8:745-754.

12. Ribeiro $L G$, Hashizume $L N$, Maltz $M$. The effect of different formulations of chlorhexidine in reducing levels of mutans streptococci in the oral cavity: A systematic review of the literature. J Dent 2007;35:359-370.

13. Rai MK, Deshmukh SD, Ingle AP, Gade AK. Silver nanoparticles: the powerful nanoweapon against multidrug-resistant bacteria. J Appl Microbiol 2012;112:841-852.

14. Zhao IS, Gao SS, Hiraishi N, Burrow MF, Duangthip D, Mei ML, et al. Mechanisms of silver diamine fluoride on arresting caries: a literature review. Int Dent J 2018;68:67-76.

15. Jowkar Z, Jowkar M, Shafiei F. Mechanical and dentin bond strength properties of the nanosilver enriched glass ionomer cement. J Clin Exp Dent 2019;11:e275-281.

16. Jowkar Z, Farpour N, Koohpeima F, Mokhtari M, Shafiei F. Effect of Silver Nanoparticles, Zinc Oxide Nanoparticles and Titanium Dioxide Nanoparticles on Microshear Bond Strength to Enamel and Dentin. J Contemp Dent Pract 2018;19:1404-1411.

17. Firouzmandi M, Shafiei F, Jowkar Z, Nazemi F. Effect of Silver Diamine Fluoride and Proanthocyanidin on Mechanical Properties of CariesAffected Dentin. Eur J Dent 2019;13:255-260.

18. Mei ML, Li QL, Chu CH, Lo EC, Samaranayake LP. Antibacterial effects of silver diamine fluoride on multi-species cariogenic biofilm on caries. Ann Clin Microbiol Antimicrob 2013;12:14.

19. Hiraishi N, Yiu CK, King NM, Tagami J, Tay FR. Antimicrobial efficacy of 3.8\% silver diamine fluoride and its effect on root dentin. J Endod 2010;36:1026-1029.

20. Mei ML, Zhao IS, Ito L, Lo EC, Chu CH. Prevention of secondary caries by silver diamine fluoride. Int Dent J 2016;66:71-77.

21. Quock RL, Barros JA, Yang SW, Patel SA. Effect of silver diamine fluoride 
on microtensile bond strength to dentin. Oper Dent 2012;37:610-616.

22. Contreras V, Toro MJ, Elias-Boneta AR, Encarnación-Burgos MA. Effectiveness of silver diamine fluoride in caries prevention and arrest: a systematic literature review. Gen Dent 2017;65:22.

23. Tang $\mathrm{S}$, Zheng J. Antibacterial activity of silver nanoparticles: structural effects. Adv Healthc Mater 2018;7:1701503-1701513.

24. You C, Han C, Wang $X$, Zheng $Y$, Li Q, Hu X, et al. The progress of silver nanoparticles in the antibacterial mechanism, clinical application and cytotoxicity. Mol Biol Rep 2012;39:9193-91201.

25. Besinis A, De Peralta T, Handy RD. The antibacterial effects of silver, titanium dioxide and silica dioxide nanoparticles compared to the dental disinfectant chlorhexidine on Streptococcus mutans using a suite of bioassays. Nanotoxicology 2014;8:1-16

26. Wu D, Fan W, Kishen A, Gutmann JL, Fan B. Evaluation of the antibacterial efficacy of silver nanoparticles against Enterococcus faecalis biofilm. J Endod 2014;40:285-290.

27. Noronha VT, Paula AJ, Duran G, Galembeck A, Cogo-Mueller K, Franz-Montan $M$, et al. Silver nanoparticles in dentistry. Dent Mater 2017;33:1110-1126.

28. Gomes-Filho JE, Silva FO, Watanabe S, Cintra LTA, Tendoro KV, Dalto LG, et al. Tissue reaction to silver nanoparticles dispersion as an alternative irrigating solution. J Endod 2010;36:1698-1702.

29. Fatemeh K, Mohammad Javad M, Samaneh K. The effect of silver nanoparticles on composite shear bond strength to dentin with different adhesion protocols. J Appl Oral Sci 2017;25:367-373.

30. Moazami F, Sahebi S, Ahzan S. Tooth discoloration induced by imidazolium based silver nanoparticles as an intracanal irrigant. J Dent 2018;19:280.

31. Shafiei F, Yousefipour B, Mohammadi-Bassir M. Effect of carbodiimide on bonding durability of adhesive-cemented fiber posts in root canals. Oper Dent 2016;41:432-440.

32. Taheri S, Cavallaro A, Christo SN, Smith LE, Majewski P, Barton M, Hayball JD, Vasilev K. Substrate independent silver nanoparticle based antibacterial coatings. Biomaterials 2014;1;35:4601-4609.

33. Gu F, Bresciani E, Barata T, Fagundes T, Navarro M, Dickens $\mathrm{S}$, et al.
In vivo acid etching effect on bacteria within caries-affected dentin. Caries Res 2010;44:472-477.

34. Sarkis-Onofre R, Skupien J, Cenci M, Moraes R, Pereira-Cenci T. The role of resin cement on bond strength of glass-fiber posts luted into root canals: a systematic review and meta-analysis of in vitro studies. Oper Dent 2014;39:E31-E44.

35. Knight GM, Mclntyre JM, Craig GG, Mulyani, Zilm PS, Gully NJ Differences between normal and demineralized dentine pretreated with silver fluoride and potassium iodide after an in vitro challenge by Streptococcus mutans. Aust Dent J 2007;52:16-21.

36. Mei ML, Ito L, Cao Y, Li QL, Chu CH, Lo EC. The inhibitory effects of silver diamine fluorides on cysteine cathepsins. J Dent 2014;42:329-335.

37. Selvaraj K, Sampath V, Sujatha V, Mahalaxmi S. Evaluation of microshear bond strength and nanoleakage of etch-and-rinse and self-etch adhesives to dentin pretreated with silver diamine fluoride/ potassium iodide: An in vitro study. Indian J Dent Res 2016;27:421.

38. Chersoni S, Acquaviva G, Prati C, Ferrari M, Grandini S, Pashley DH, et al. In vivo fluid movement through dentin adhesives in endodontically treated teeth. J Dent Res 2005;84:223-227.

39. Pisani-Proença J, Erhardt MCG, Amaral R, Valandro LF, Bottino MA Del Castillo-Salmerón R. Influence of different surface conditioning protocols on microtensile bond strength of self-adhesive resin cements to dentin. J Prosthet Dent 2011;105:227-235.

40. Mei ML, Li Q, Chu C, Yiu CK, Lo EC. The inhibitory effects of silver diamine fluoride at different concentrations on matrix metalloproteinases. Dent Mater 2012;28:903-908.

41. Mei $\mathrm{ML}$, Ito $\mathrm{L}, \mathrm{Cao} \mathrm{Y}, \mathrm{Li} \mathrm{QL}$, Lo $\mathrm{EC}$, Chu $\mathrm{CH}$. Inhibitory effect of silver diamine fluoride on dentine demineralisation and collagen degradation. J Dent 2013;41:809-817.

Received February 28, 2020 Accepted April 20, 2020 